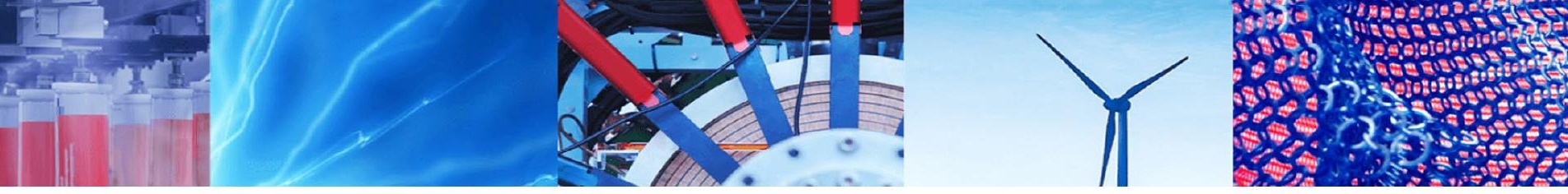

Research Article

\title{
Performance of plastic waste for soil improvement
}

\author{
Rowad Esameldin Farah ${ }^{1} \cdot$ Zalihe Nalbantoglu $^{1}$
}

(c) Springer Nature Switzerland AG 2019

\begin{abstract}
Recycling plastic waste from water bottles has become one of the main challenges worldwide. The aim of this study is to recycle empty plastic water bottles as reinforcing material for the improvement of sandy soil. The laboratory tests were performed on both natural and reinforced sands with different plastic waste percentages: $0,0.5,0.75$ and 1.0 of the dry weight of sand at relative density states of $30 \%$ and $60 \%$. Direct shear box and the California Bearing Ratio, CBR tests were performed to determine the effect of the plastic waste on the shear strength and the penetration resistance of the reinforced sand. Test results indicated that plastic waste reinforcement contributed to the improvement of the shear strength and the CBR number of the reinforced sand. Higher shear strength and higher penetration resistance were obtained with plastic waste reinforcement. The optimum percentage of plastic waste required for enhancing the shear strength and the CBR number was found to be $0.75 \%$. With the optimum percentage of plastic waste, the improvement in the shear strength and the penetration resistance of the reinforced sand increased to at least $9 \%$ compared to natural soil at relative density states of $30 \%$ and $60 \%$.
\end{abstract}

Keywords Plastic $\cdot$ Recycle $\cdot$ Reinforcement $\cdot$ Shear strength $\cdot$ Waste

Abbrevations

ASTM American society for testing and materials

CBR California bearing ratio

PET Polyethyethylene terephthalate

\section{List of symbols}

c Cohesion

$C_{c} \quad$ Coefficient of curvature

$\mathrm{C}_{\mathrm{u}} \quad$ Coefficient of uniformity

${ }^{\circ} \mathrm{C} \quad$ Celsius

e Void ratio

$e_{\max } \quad$ Maximum void ratio

$\mathrm{e}_{\min } \quad$ Minimum void ratio

$G_{s} \quad$ Specific gravity

SP Poorly graded sand

$\rho_{\mathrm{d}(\max )} \quad$ Maximum index density

$\rho_{\mathrm{d}(\mathrm{min})} \quad$ Minimum index density

$\phi_{\text {peak }}$ Peak internal friction angle

$\phi_{\text {cri }} \quad$ Critical internal friction angle

$D_{r} \quad$ Relative density

\section{Introduction}

Literature review [1] indicated that the usage of water bottles has enlarged by around 500\% throughout the previous decade, and 1.5 million tons of plastic is utilized to bottle water each year. Chen et al. [2] stated that finding a way to reuse plastic waste is an environmentally friendly approach to reduce greenhouse gas (GHG) emission and fossil fuel consumption. In some field conditions, soil stabilization techniques are required to agree with particular engineering projects in terms of soil properties [3]. The most effective technique to improve the soft ground is insitu deep mixing [4-6], so the soil can be mixed with plastic waste as reinforcing material. To enhance the environmental acceptability and decrease the construction cost of traditional stabilization such as cement and lime, the replacement of them by plastic waste can be one of the alternatives.

There are limited researches performed on the usage of plastic bottle waste as a reinforcing material for soil

Rowad Esameldin Farah, rowad.farah@cc.emu.edu.tr; Zalihe Nalbantoglu, zalihe.nalbantoglu@emu.edu.tr| ${ }^{1}$ Department of Civil Engineering, Eastern Mediterranean University, Via Mersin 10, Famagusta, North Cyprus, Turkey.

SN Applied Sciences (2019) 1:1340 | https://doi.org/10.1007/s42452-019-1395-2

Received: 7 August 2019 / Accepted: 1 October 2019 / Published online: 5 October 2019 
improvement. Researchers have focused on using the waste of plastic bottles as reinforcing material in the sand $[1,7]$. The plastic waste has been added in the form of chips in different percentages. The experimental outcomes have illustrated that the inclusion of plastic waste chips improved the shear strength of sandy soil due to the increase in friction between the soil particles and the plastic waste $[1,7]$. Consoli et al. [8] used polyethylene fibers extracted from plastic wastes for reinforcing cemented and uncemented sand. The findings of the study illustrated that plastic waste improved the stress-strain response of both cemented and uncemented sands. Boter et al. [9] studied the effect of the plastic waste material on the shear strength of silty soil. The test results indicated that the increase in plastic waste material decreased the internal friction angle, whereas an increase in the cohesion value was obtained. Researchers concluded that the inclusion of plastic waste (fiber reinforcement) enhances the strength and stability of soils [10-12]. Yetimoglu and Salbas [13] have conducted an experimental study to evaluate the effectiveness of randomly distributed discrete fibers on shear strength of sand by conducting direct shear tests. Test results indicated that the introduction of fibers into the soil has enhanced the residual strength taking place after peak stress and decreased the brittle character of soil. Dos Santos et al. [14] have investigated the effect of Polypropylene fiber on the shear strength of sandy soils under different confining stresses. The test results exhibited that the shear strength of soil mainly depended on testing confining stresses. Moreover, the inclusion of fibers has appealed a reduction in shear strength of fiber-reinforced soil with an increase in confining stress.

Nagrale et al. [15] conducted a study on the improvement of CBR value of subgrade soil (fine sand and clay soil) with the addition of polypropylene fibers, and they concluded that the fiber enhanced CBR value of soils. Choudhary et al. [16] have performed California Bearing Ratio (CBR) tests on soil that has been reinforced by highly density polyethylene strips (HDPE). The high density polyethylene strips were randomly distributed with the soil with different percentages and lengths. The CBR test results showed that the introduction of waste HDPE strips in soil with suitable amounts improved the strength and deformation character of subgrade soils remarkably.

All the previous investigations have presented that the introduction of fiber caused a significant enhancement in shear strength of fiber-reinforced soils. The randomly spread fiber could be considered as a good enhancement material which leads to a remarkable improvement in the engineering index properties of sand. While efforts have also been made to examine the influence of fiber on the penetration resistance of reinforced soil (CBR test). Nevertheless, there is limited literature on the influence of fiber content on both shear strength and penetration resistance of reinforced sand soil. Consequently, the reinforced soil with fiber requires more investigations. This research aims to investigate the effect of introducing plastic waste chips with various percentages on the shear strength and penetration resistance of sand with two different relative densities, $30 \%$, and $60 \%$.

\section{Materials and sample preparation}

In the study, all the laboratory tests were performed on dry sand. Before testing, the sand was kept in an oven at 110 degree Celsius for at least $24 \mathrm{~h}$. The sieve analysis was carried out to determine the particle sizes of the sand, and the results were used for the classification of the sand. Direct shear tests have been conducted on natural and plastic chips reinforced sand to determine the shear strength parameters before and after reinforcement. The CBR tests were performed for the evaluation of the effect of plastic waste on the subgrade strength of pavements by determining the maximum penetration of the natural and the plastic chips reinforced sands.

\subsection{Beach sand}

In this study, the sand was taken from the sea coast of Famagusta in North Cyprus. The particle size distribution curve of this sand was given in Fig. 1. According to the Unified Soil Classification System (ASTM D 2487-00), the coefficient of curvature $\left(C_{c}\right)$ was 0.91 which is less than 1 , the coefficient of uniformity $\left(C_{\mathrm{u}}\right)$ was 1.78 which is less than $6, D_{60}, D_{30}$ and $D_{10}$ were $0.32,0.23$ and 0.18 , respectively. The result of soil classification is mentioned in the results and discussion section. The physical properties of the sand were given in Table 1.

\subsection{Plastic bottles}

The empty plastic water bottles were collected from various cafeterias in Eastern Mediterranean University campus in North Cyprus. The plastic bottle waste used in this study was polyethylene terephthalate (PET). After collecting the plastic bottles, they were first cut into small sizes and then into strips. By using a scissor, these strips were then cut into small chips.

In the literature, different sizes of plastic chips were used in correspondence to aspect ratios (length/width). Benson and Khire [17] have used plastic strips with a width of $6 \mathrm{~mm}$ and lengths of 24, 48, and $72 \mathrm{~mm}$ (aspect ratios of 4,8 and 12) to study the effect of them on shear strength of the soil. Babu and Chouksey [1] used a plastic chip size of $12 \mathrm{~mm}$ long and $4 \mathrm{~mm}$ in width to see the response of 
Fig. 1 Particle size distribution curve for natural beach sand

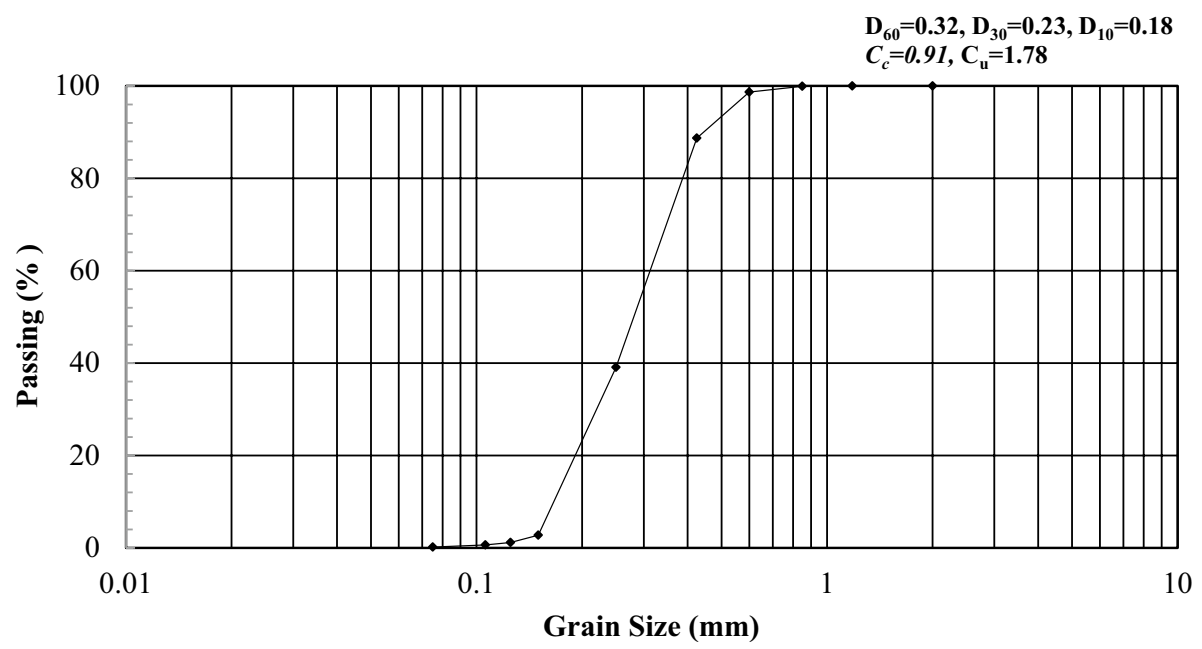

Table 1 Physical properties of the natural beach sand

\begin{tabular}{|c|c|}
\hline Physical properties & Values \\
\hline Minimum void ratio ${ }^{a}, e_{\min }$ & 0.55 \\
\hline Maximum void ratio ${ }^{a}, e_{\max }$ & 0.73 \\
\hline Minimum index density ${ }^{\mathrm{a}}, \rho_{\mathrm{d}(\mathrm{min})}\left(\mathrm{g} / \mathrm{cm}^{3}\right)$ & 1.57 \\
\hline Maximum index density ${ }^{\mathrm{a}}, \rho_{\mathrm{d}(\max )}\left(\mathrm{g} / \mathrm{cm}^{3}\right)$ & 1.76 \\
\hline Specific gravity $^{\mathrm{b}}$, (Gs) & 2.72 \\
\hline Coefficient of uniformity ${ }^{c}, C_{u}$ & 1.78 \\
\hline Coefficient of curvature ${ }^{c}, C_{c}$ & 0.91 \\
\hline Soil classification $^{d}$ & SP \\
\hline
\end{tabular}

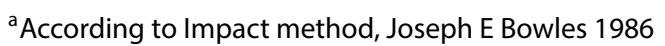

${ }^{\mathrm{b}}$ According to ASTM D 854-06

${ }^{\mathrm{C}}$ According to ASTM D 2487-06

${ }^{d}$ According to ASTM D 2487-00 (Unified Soil Classification System)

it in bearing capacity improvement and settlement reduction. Plastic bottle fibers have been used in three different aspect ratios $2(10 \mathrm{~mm} \times 5 \mathrm{~mm}), 4(10 \mathrm{~mm} \times 2.5 \mathrm{~mm})$ and 8
$(10 \mathrm{~mm} \times 1.25 \mathrm{~mm})$ to see the effect of them on compaction characteristics and consolidation behavior of soil [18]. Since, there is no specific size in the literature the size of approximately $12 \mathrm{~mm}$ length, $4 \mathrm{~mm}$ width and thickness of $0.3 \mathrm{~mm}$ (aspect ratio $\mathrm{f} 3$ ) with specific gravity of 1.0 were utilized in this study. A photo of the plastic chips used in this study was given in Fig. 2 .

\section{Methods}

\subsection{Minimum index density and maximum void ratio, $\rho_{d(\min )}$ and $e_{\max }$}

This test was conducted according to the impact method suggested by Bowel [19]. Also, to obtain the maximum void ratio of the sand at the loosest condition, the dry sand was poured into a mold by using a small funnel. With the known weight and the volume of the mold, the maximum void ratio, $e_{\max }$ of the sand was determined.
Fig. 2 Plastic bottles chips used as a reinforcing material in this study

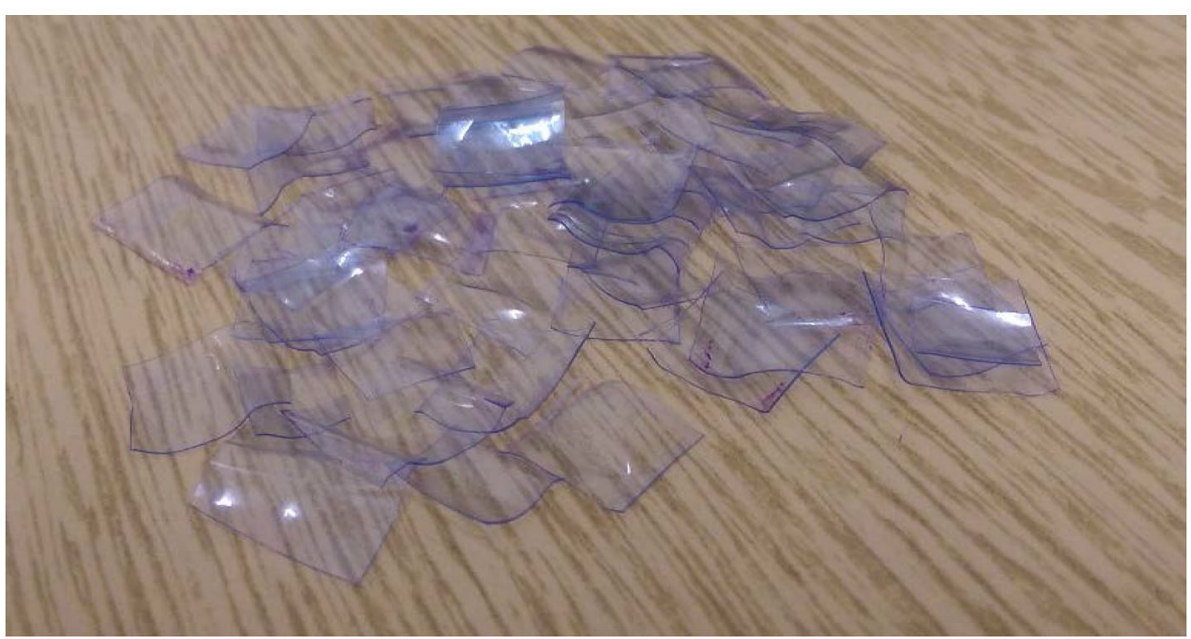

SN Applied Sciences A SPRINGER NATURE journa 


\subsection{Maximum index density and minimum void ratio, $\rho_{d(\max )}$ and $e_{\min }$}

According to Bowel [19], the impact method was also used for finding the maximum index density of the sand. The oven-dried sand was poured into the mold by using the small funnel in five successive layers. Each layer was compacted according to the impact method proposed by Bowel [19], from the known volume of the mold and the weight of the compacted sand inside the mold, the maximum index density, $\rho_{\mathrm{d}(\max )}$, and the minimum void ratio, $\mathrm{e}_{\text {min }^{\prime}}$ of the sand was determined.

\subsection{Direct shear box test}

In this study, the sand specimens were prepared at 30\% and $60 \%$ relative density values using Eq. 1 .

$D_{r}=\frac{e_{\max }-e}{e_{\max }-e_{\min }}$

where $D_{r}$ : relative density, $e_{\max }=$ maximum void ratio, $e_{\min }=$ minimum void ratio, $e=$ void ratio of the sand specimens.

The sand specimens were compacted in the direct shear box at $30 \%$ and $60 \%$ relative density values. The void ratio of the sand prepared at $30 \%$ (loose state) and $60 \%$ (dense state) relative density values were calculated to be 0.676 and 0.622 , respectively. For $30 \%$ relative density state, the soil mass was poured in one layer with a slight vibration and tamped to reach the required density state in the box. For $60 \%$ relative density state, the soil was poured in three successive layers, each layer was slightly shaken and tamped to reach the desired relative density state. For the reinforced soil, the specified weight of plastic waste percent by dry weight of soil was distributed uniformly over the soil and mixed uniformly, and same procedure as for natural soil was then followed. The sand specimens were subjected to three different normal stress values: 20,30 , and $50 \mathrm{kPa}$ and the shear strength parameters were determined. The rate of shear displacement applied in the study is $1.06 \mathrm{~mm} / \mathrm{min}$, according to Prakash [20].

The shear stress versus horizontal displacement curves obtained for the natural beach sand under different normal stress values was given in Figs. 3 and 4. The curves in Fig. 3 represented the values of the sand prepared at $30 \%$ relative density value whereas, in Fig. 4 , the sand specimens were prepared at $60 \%$ relative density. From the curves obtained in Figs. 3 and 4, the peak and the critical friction angles of the natural beach sand were determined at $30 \%$ and $60 \%$ relative density values by using the maximum and critical shear stress values. Then, these values were used with the corresponding normal stresses values to get the shear strength parameters.

\subsection{California bearing capacity ratio, CBR test}

The CBR test is a penetration test for evaluating the bearing capacity of subgrade soil for road and pavement [14]. In this study, the CBR test was performed to assess the effectiveness of plastic waste on the penetration resistance of the $0.75 \%$ plastic chips reinforced sand. The sand specimens were prepared at relative density values of 30 and $60 \%$.
Fig. 3 Shear stress versus horizontal displacement curves for the natural beach sand prepared at $30 \%$ relative density

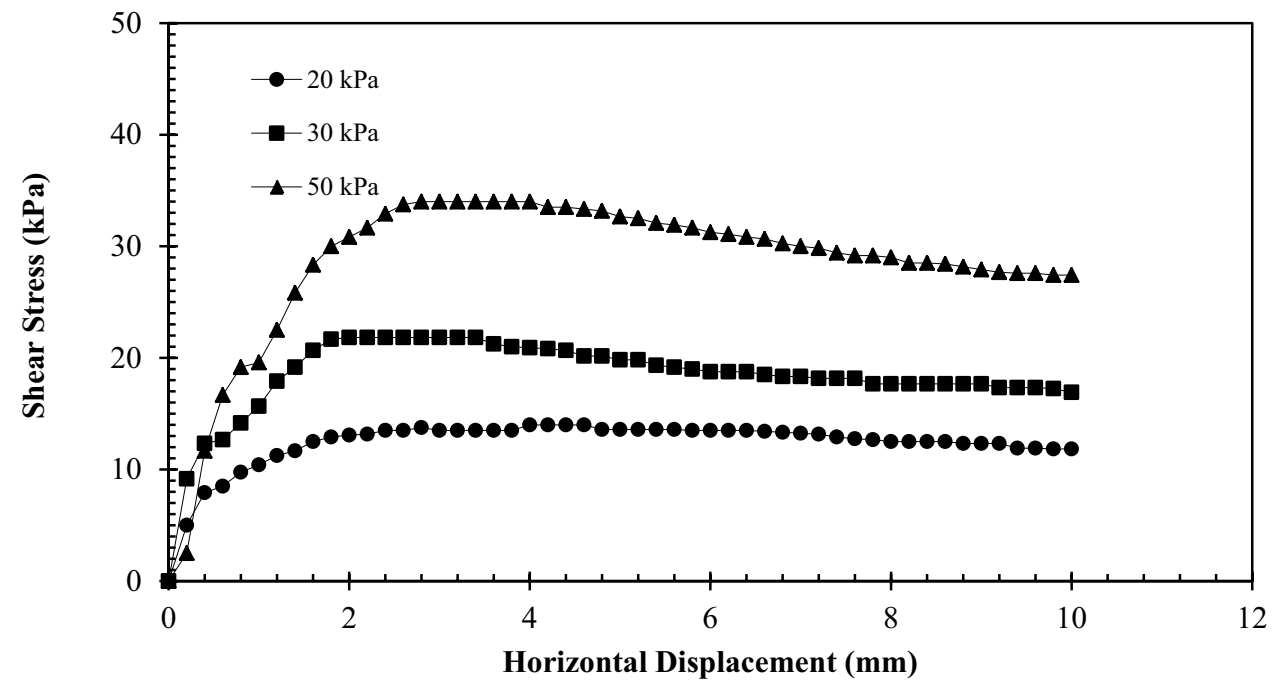


Fig. 4 Shear stress versus horizontal displacement curves for the natural beach sand Prepared at $60 \%$ relative density

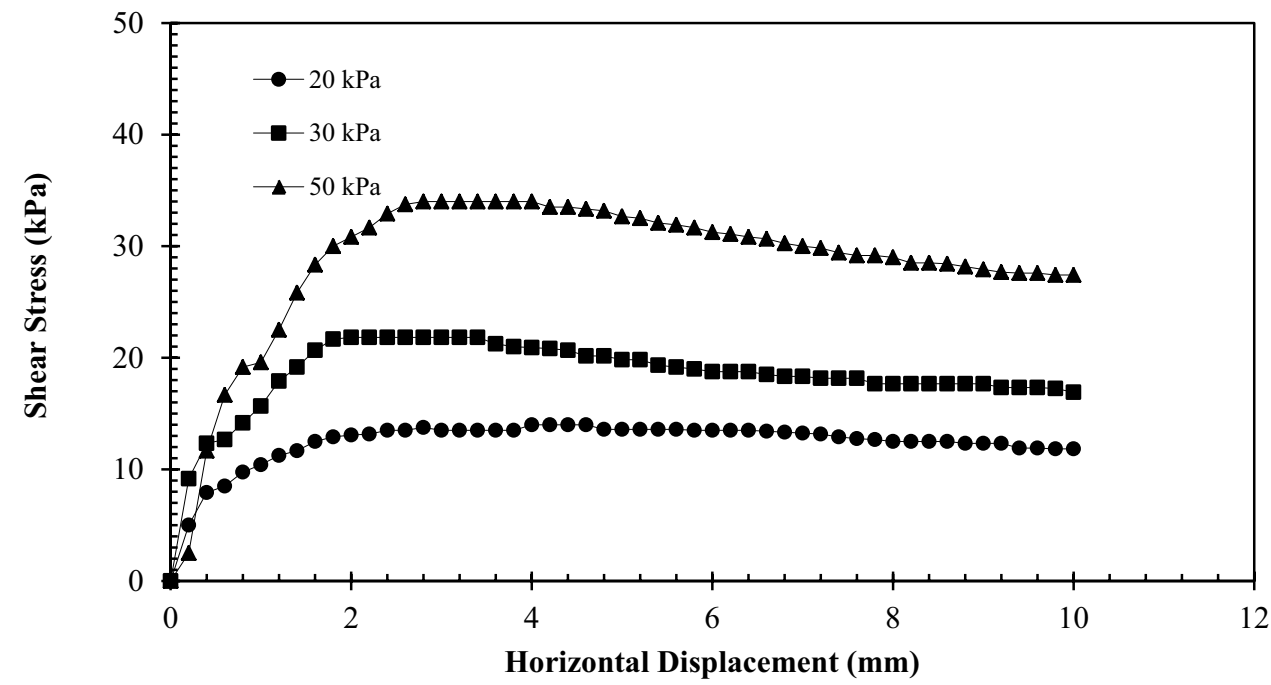

Table 2 The internal friction angles for natural and reinforced sand at $30 \%$ relative density

\begin{tabular}{lcccc}
\hline Internal friction angle & \multicolumn{5}{c}{ Plastic percentage } \\
\cline { 2 - 5 } & 0 & 0.50 & 0.75 & 1.0 \\
\hline Peak internal friction angle, $\phi_{\mathrm{p}}$ & $33^{\circ}$ & $34^{\circ}$ & $36^{\circ}$ & $34^{\circ}$ \\
Critical internal friction angle, $\phi_{\text {cri }}$ & $18^{\circ}$ & $30^{\circ}$ & $33^{\circ}$ & $32^{\circ}$ \\
\hline
\end{tabular}

\section{Results and discussion}

According to the Unified Soil Classification System (ASTM D 2487-00), the soil was classified as poorly graded sand (SP).

\subsection{Direct shear box test}

From the curves obtained in Figs. 3 and 4, the peak and the critical friction angles of the natural beach sand were determined at $30 \%$ and $60 \%$ relative density values. The peak internal friction angle, $\phi_{\mathrm{p}}$ of the natural beach sand prepared at $30 \%$ relative density gave a value of $33^{\circ}$ whereas the peak internal friction angle at $60 \%$ relative density was found to be $34^{\circ}$. Also, the critical internal friction angles of the natural beach sand at $30 \%$ and $60 \%$ relative densities were found to be $18^{\circ}$ and $30^{\circ}$, respectively.

The shear strength parameters of the natural and the plastic waste reinforced sand obtained from the direct shear box tests were given in Tables 2 and 3 . The values in Tables 2 and 3 presented the peak $\phi_{\mathrm{p}}$ and the critical friction angle, $\phi_{\text {cri }}$ of the sand specimens prepared at $30 \%$ and $60 \%$ relative density values, respectively. Generally,
Table 3 The internal friction angles for natural and reinforced sand at $60 \%$ relative density

\begin{tabular}{lcccc}
\hline Friction angle & \multicolumn{4}{c}{ Plastic percentage } \\
\cline { 2 - 5 } & 0 & 0.50 & 0.75 & 1.0 \\
\hline Peak internal friction angle, $\phi_{\mathrm{p}}$ & $34^{\circ}$ & $35^{\circ}$ & $37^{\circ}$ & $34^{\circ}$ \\
Critical internal friction angle, $\phi_{\text {cri }}$ & $30^{\circ}$ & $30^{\circ}$ & $33^{\circ}$ & $30^{\circ}$ \\
\hline
\end{tabular}

test results indicated an increase in the peak and critical friction angles of the plastic chip reinforced sand due to the increase in the frictional strength between the sand particles. Test results also indicated that mixing of sand with $0.5 \%$ and $0.75 \%$ plastic waste caused an increase in the peak and the critical friction angles, in all cases of reinforced sand soil the cohesion was about $1 \mathrm{kPa}$ and no changes were confronted. The results also indicated that with increasing relative density, the peak internal friction angles were increased due to the increase in the interlocking of the sand particles. In addition to that, the increase in the shear strength of reinforced soil with strips could be explained because of the generated tension in the shear region due to the occurred anchorage at the soil/reinforcement interface outer the shear region. The generated tension in the strips adds to the shear strength of soil. Moreover, the strips are retained in tension even after reaching the peak strength. Therefore, the post-peak loss in shear strength is lesser than would be noticed in unreinforced specimens [10]. As it can be seen in Fig. 5. On the other hand, the comparison of the results in Tables 2 and 3 on reinforced soil of loose and dense states (30\% and 60\%) showed that the plastic inclusion contributed in a slighter or marginal role in the critical internal friction angle in the densely packed soil (60\% relative density) compared to loosely packed 


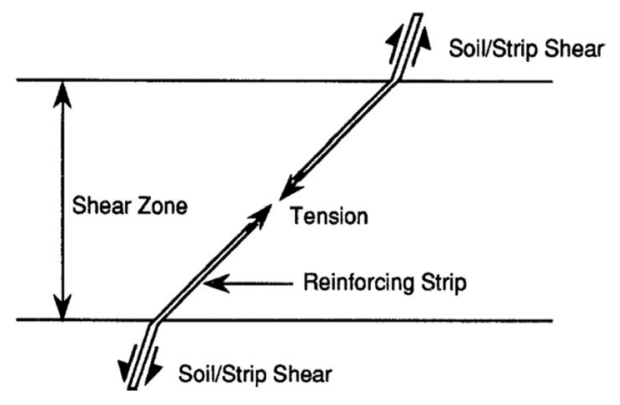

Fig. 5 Mechanism of soil reinforcement, Gray and Ohashi [10]

Table 4 shows the percentage of increase in internal friction angles in case optimum percentage of plastic chips with $30 \%$ relative density state

\begin{tabular}{lc}
\hline Internal friction angle & $\begin{array}{l}\text { \% increase in } \\
\text { internal friction } \\
\text { angle }\end{array}$ \\
\hline Peak internal friction angle, $\phi_{\mathrm{p}}$ & 9 \\
Critical internal friction angle, $\phi_{\mathrm{cri}}$ & 83 \\
\hline
\end{tabular}

Table 5 shows the percentage of increase in internal friction angles in case optimum percentage of plastic chips with $60 \%$ relative density state

\begin{tabular}{lc}
\hline Internal friction angle & $\begin{array}{l}\text { \% increase in } \\
\text { internal friction } \\
\text { angle }\end{array}$ \\
\hline Peak internal friction angle, $\phi_{\mathrm{p}}$ & 9 \\
Critical internal friction angle, $\phi_{\mathrm{cri}}$ & 10 \\
\hline
\end{tabular}

soil (30\%). In the densely packed soil, sliding of particles likely happens on the smooth surface of plastic chips. This sliding prevents bending-stretching of plastic chips and leads to a restricted generation of plastic chips tensile stress and, therefore, shearing resistance.

However, no further improvement in the friction angle of the sand was obtained above $0.75 \%$ plastic waste. Above this value, there was no contribution to the improvement of the shear strength parameters of the reinforced sand. The reinforcing effect of plastic waste diminished. The reinforcement effect can be explained due to the breakage of the frictional bond between the sand particles and the plastic chips above $0.75 \%$ plastic waste. Weaker bonding between the sand particles and the plastic chips resulted in lower internal friction angle.

In this study, the optimum percentage of plastic chips to improve the shear strength was found to be $0.75 \%$. This result was in good agreement with the findings of Poweth et al. [21]. Tables 4 and 5 show the percentage of increase in internal friction angles in case of optimum
Table 6 CBR numbers for natural, $0.75 \%$ plastic waste reinforced sand and its percent of increase

\begin{tabular}{lllc}
\hline $\begin{array}{l}\text { Relative } \\
\text { density (\%) }\end{array}$ & $\begin{array}{l}\text { CBR number of } \\
\text { natural sand }\end{array}$ & $\begin{array}{l}\text { CBR number of } \\
\text { 0.75\% reinforced } \\
\text { sand }\end{array}$ & $\begin{array}{l}\text { \% increase in } \\
\text { CBR number }\end{array}$ \\
\hline 30 & 9 & 10 & 11 \\
60 & 11 & 12 & 9 \\
\hline
\end{tabular}

percentage of plastic chips with $30 \%$ and $60 \%$ relative density states.

\subsection{California bearing capacity ratio, CBR}

In the CBR tests, the optimum percentage of plastic waste: $0.75 \%$ was used, and the sand specimens were prepared in the CBR mold at $30 \%$ and $60 \%$ relative density values. The CBR numbers obtained for the natural and $0.75 \%$ reinforced sand at $30 \%$ and $60 \%$ relative densities were given in Table 6. The values in Table 6 indicated that $0.75 \%$ plastic waste reinforcement caused a slight increase in the CBR number. The slight increment in the CBR number can be attributed to the strong binding between the sand particles and the plastic chips, resulting in higher penetration resistance of the reinforced sand. This result was in good agreement with the findings of Poweth et al. [21] as the $0.75 \%$ of plastic increased the CBR number of soil, even though in their study the plastic was in the form of granules but same behavior was confronted. The same table, Table 6, shows the percent of increase in CBR number of reinforced sand compared to natural sand. According to Bowel [19], the obtained CBR numbers indicated that the reinforced sand could be used as sub-base materials for road and pavement constructions.

\section{Practical implications of the study}

In this study, the cutting of plastic bottles into small chips was time-consuming and very difficult to attain the required size as described in materials and methods section.

In this study, the distribution of higher percentages of plastic chips with sand was difficult to attain uniform mixtures.

For further studies, it is better to search for recycling industries, which most probably may help to get the required material in different shapes and sizes.

For further studies, different percentages and sizes of plastic waste should be used. Besides, another cementing material can be blended with plastic chips such as lime and cement to increase its effect on geotechnical properties of soils. 


\section{Conclusions}

Based on the experimental work carried out on natural and plastic waste reinforced beach sand, the test results of this study indicated that recycling of plastic waste bottles is possible. The improvement in the shear strength and the CBR number of plastic waste reinforced sand is encouraging. Based on results of tests the following conclusions could be drawn:

The inclusion of plastic chips of waste bottles into the sand increased the shear strength of the sand. The optimum percentage of the plastic chip was found to be $0.75 \%$. The values of the peak and the critical internal friction angles increased with an increase in the percent of plastic chips up to $0.75 \%$. The addition of plastic chips beyond $0.75 \%$ decreased the peak internal friction angle. That means the reinforcing effect of plastic waste on the shear strength of sand diminished.

The $0.75 \%$ plastic chip reinforcement resulted in a positive improvement in the CBR number. With $0.75 \%$ plastic chip reinforcement, the reinforced sand showed higher resistance to penetration, leading to an increase in the CBR number.

In the case of 30 and $60 \%$ relative densities, the inclusion of the optimum plastic percentage $(0.75 \%)$ improved the peak, critical internal friction angles and CBR numbers of sand soils by at least $9 \%$.

In this study, only one percentage of plastic chips were used (optimum percentage in case of shear strength) to study the CBR values. For future studies, different percentages and sizes of plastic waste should be utilized to indicate whether the $0.75 \%$ of plastic chips is an optimum percentage also for resistance penetration in reinforced sand as in the case of shear strength.

Acknowledgements The support and facilities of this research to be accomplished returning to Eastern Mediterranean University, Civil Engineering Department.

\section{Compliance with ethical standards}

Conflict of interest The authors declare that they have no conflict of interest.

\section{References}

1. Babu GS, Chouksey SK (2011) Stress-strain response of plastic waste mixed soil. Waste Manag 31(3):481-488

2. Chen X, Xi F, Geng Y, Fujita T (2011) The potential environmental gains from recycling waste plastics: simulation of transferring recycling and recovery technologies to Shenyang. Waste Manag 31(1):168-179
3. Rogers CDF, Glendinning S, Roff TEJ (1997) Lime modification of clay soils for construction expediency. In: Proceeding of the institution of civil engineers: geotechnical engineering, vol 125, p 4

4. Kawasaki T (1981) Deep mixing method using cement hardening agent. In: Proceedings of 10th international conference on SMFE, pp 721-724

5. Bruce DA. Bruce MEC, Dimillio AF (1999) Dry mix methods: a brief overview of international practice. In: Proceedings of international conference on dry mix methods for deep soil stabilization. Balkema, Rotterdam, pp 15-25

6. Saitoh S, Suzuki Y, Shirai K (1985) Hardening of soil improved by deep mixing method. In: Proceeding of 11 th international conference on soil mechanics and foundation engineering, San Francisco, Publication of: Balkema (AA), pp 12-16

7. Dutta RK, Dutta K, Jeevanandham S (2015) Prediction of deviator stress of sand reinforced with waste plastic strips using neural network. Int J Geosynth Ground Eng 1(2):11

8. Consoli NC, Montardo JP, Prietto PDM, Pasa GS (2002) Engineering behavior of a sand reinforced with plastic waste. J Geotech Geoenviron Eng 128(6):462-472

9. Botero E, Ossa A, Sherwell G, Ovando-Shelley E (2015) Stressstrain behavior of a silty soil reinforced with polyethylene terephthalate (PET). Geotext Geomembr 43(4):363-369

10. Gray DH, Ohashi H (1983) Mechanics of fiber reinforcement in sand. J Geotech Eng 109(3):335-353

11. Vijayasingam B, Heng GY (2003) The laboratory study of granular soils reinforced with randomly oriented distributed flexible fibres. Major Research Project University of Bristol, p 45

12. Kar RK, Pradhan PK, Naik A (2012) Consolidation characteristics of fiber reinforced cohesive soil. Electron J Geotech Eng 17:3861-3874

13. Yetimoglu T, Salbas O (2003) A study on shear strength of sands reinforced with randomly distributed discrete fibers. Geotext Geomembr 21(2):103-110

14. Dos Santos AS, Consoli NC, Baudet BA (2010) The mechanics of fibre-reinforced sand. Geotechnique 60(10):791

15. Nagrale PP, Chandra S, Viladkar MN (2005) Behaviour of flexible pavements resting on fiber reinforced subgrade soils. In: Proceedings of Indian geotechnical conference, Ahmedabad India 185-188

16. Choudhary AK, Jha JN, Gill KS (2010) A study on CBR behavior of waste plastic strip reinforced soil. Emirates J Eng Res 15(1):51-57

17. Benson $\mathrm{CH}$, Khire MV (1994) Reinforcing sand with strips of reclaimed high-density polyethylene. J Geotech Eng 120(5):838-855

18. Laskar A, Pal SK (2013) Effects of waste plastic fibres on compaction and consolidation behavior of reinforced soil. Electron $J$ Geotech Eng 18:1547-1558

19. Bowel JE (1986) Engineering properties of soils and their measurements, 3rd edn. McGraw-Hill, Inc, New York

20. Prakash S (1995) Fundamental of soil mechanics. Shamsher Prakash Foundation

21. Poweth MJ, Haneef FM, Jacob MT, Krishnan R, Rajan S (2014) Effect of plastic granules on the properties of soil. Int J Eng Res Appl 4(4):160-164

Publisher's Note Springer Nature remains neutral with regard to jurisdictional claims in published maps and institutional affiliations. 